\title{
PROCEEDINGS AND REPORTS OF UNIVERSITIES COLLEGES, COUNCILS AND ASSOCIATIONS
}

\author{
GREAT BRITAIN \\ UNIVERSITY OF LIVERPOOL \\ DEGREE OF M.Ch.(Orth.) 1956
}

Seven candidates were successful in gaining this degree. They were: R. M. Bhansali (Bombay, India); J. C. N. Joshipura (Bombay, India); A. H. McKenzie (Alberta, Canada); R. B. J. Peiris (Colombo, Ceylon); A. E. Pritchard (Liverpool, England); S. K. Roy (Patna, India); and W. A. L. Thompson (Liverpool, England). The external examiners were Sir Harry Platt of Manchester and Mr J. M. Edelstein of Johannesburg, South Africa. The internal examiners were Professor Bryan McFarland, Mr Norman Roberts and Mr Eric Wardle.

\section{UNIVERSITY OF OXFORD}

NUFFIELD ORTHOPAEDIC CENTRE

Lectures delivered during the Hilary Term included: "Avascular necrosis of the femoral head: a clinical and experimental study," by Mr T. J. Claffey; and "Biomechanical problems in the reconstruction of the femur," by Mr J. M. Zarek.

The two remaining lectures in this series are on "Some surgical aspects of the rheumatoid hand," by Mr O. J. Vaughan-Jackson (February 28 at 8.30 p.m.); and "Volkmann's contracture: second thoughts," by Mr D. Ll. Griffiths (March 14 at 8.30 p.m.).

\section{SCIENTIFIC SOCIETIES AND REGIONAL ORTHOPAEDIC CLUBS}

\section{SOUTH-EAST METROPOLITAN REGION ORTHOPAEDIC CLUB}

A meeting was held at Lewisham General Hospital on November 10, 1956, at which a large selection of cases was demonstrated by Mr A. C. Bingold and Mr W. G. France.

Osteochondritis dissecans-Mr Bingold showed two patients with osteochondritis dissecans of the knee upon whom he had operated recently. In one case iliac chips were held in position with a plug of fibrin foam; in the other, thrombin and fibrinogen were used to fix iliac chips and a cartilage graft. Both patients said that their knees felt normal. Mr Bingold illustrated his description of the operation with coloured slides. Discussion centred round the various operative procedures for this condition, and more than one member reported favourably upon results of operations carried out by Smillie's methods.

Congenital dislocation of hip-Mr France showed a series of children with congenital dislocation of the hip presenting problems in treatment. Mr Bingold was congratulated particularly on the outcome of a Colonna operation performed on one such patient.

Bone tumours-Mr Bingold and Mr France showed a series of bone tumours treated by excision and replacement by internal prostheses.

Pectoral transplant-Mr France discussed Clark's pectoral transplant for paralysis of the biceps brachii. This operation found wide support at the meeting. Several members emphasised the need for great caution before deciding upon arthrodesis of the shoulder in paralytic lesions of the upper limb.

Central-dislocation operation for osteoarthritis of hip-Mr France demonstrated a series of patients subjected to Charnley's operation for osteoarthritis of the hip. Very few of these had resulted in fusion of the joint, but pain had been relieved in each case. Mr S. A. Jenkins maintained that the use of large quantities of cancellous bone chips helped greatly in securing arthrodesis. $M r O$. J. Vaughan-Jackson had found Charnley's operation useful but reported cases of apparent subsequent fractures of the femoral neck which he was inclined to regard as pseudo-fractures resulting from damage to the blood supply during the operation. 
SOUTH-WEST ORTHOPAEDIC CLUB

The autumn meeting of the South-West Orthopaedic Club was held at Winford Orthopaedic Hospital on November 17, 1956. The Chairman was Mr K. H. Pridie.

Stainless steel staple fixation for arthrodesis- $M r K$. H. Pridie showed patients in whom this method had been used to maintain fixation for arthrodesis of the knee and the metatarso-phalangeal joint of the big toe. As many as six staples had been employed at the knee when the bone was soft. No plaster fixation had been used.

Cartilage grafts in osteochondritis dissecans of the knee-Mr Pridie showed three patients with normal function in the knee and a nearly normal radiograph after an operation for removal of the osteochondritic area. The defect had been filled with cancellous bone taken from the upper end of the tibia and the cartilage graft had been taken from the opposite femoral condyle and superimposed. After the operation plaster fixation was necessary for three months. The longest follow-up was three years.

Osteosclerosis of the tibia simulating osteoid osteoma-Mr Pridie showed a patient in whom a zone of sclerosis occurred around a small piece of steel which had been chipped off an osteotome during removal of part of the tibia for a spine grafting operation. The patient had pain for four years before relief was obtained by resection of the area containing the foreign body.

Late results of arthroplasty of the elbow-Mr $A$. L. Eyre-Brook showed five patients. The operation had been performed for tuberculosis (once), injury (twice), osteoarthritis (once) and rheumatoid arthritis (once). Two patients were able to do heavy work. In three cases in which fascia had been interposed between the bone ends, the results were not so satisfactory as those in which it had been avoided, and the elbows were less stable. Mr Eyre-Brook said that he always preferred to fashion the bone ends because the arthroplasty gained greater stability thereby. He doubted whether arthrodesis of the elbow should be advised in view of the satisfactory functional result that an arthroplasty could give.

Congenital deformities-Mr Eyre-Brook showed a boy of fourteen with congenital fusion of the greater multangular and navicular bones of the carpus of both wrists. There was also absence of the muscles of the thenar eminences. He had no serious functional disability. $M r D$. M. Jones showed two children with congenital absence of the radius. In one the upper part of the fibula including the epiphysis had been grafted into the ulna. Eleven months later the epiphysis of the fibula remained open and appeared to be growing, but the growth of the transplanted fibula was not keeping pace with the ulna, and the deformity was tending to increase again. Mr Jones also showed a child with congenital varus deformity of the tibia which had been treated successfully by osteotomy-osteoclasis.

Arthrodesis of the hip-Mr M.P. McCormack showed two patients with arthrodesis of the hip carried out by the Pyrford method of nail fixation with subtrochanteric osteotomy. This had been performed in one after failure of operative treatment for slipped epiphysis. Mr McCormack had used the method on nine occasions with success and preferred it to other methods of arthrodesis.

Complete tetraplegia-Mr Keith Lucas described the case of a young seaman of thirty who suffered tetraplegia after a fracture-dislocation of the neck at C.4-5. There had been no neurological recovery but the patient was now able to sit up in a chair. He could now paint by holding a brush in his mouth. With skilled nursing, bedsores had been avoided.

Tenosynovitis of the flexor tendons of the hand-Mr $N$. Alms showed two cases of tenosynovitis of the flexor sheaths of the hand with pain in the fingers which had been cured by injection of a mixture of Xylocaine and hydrocortisone. He said that it was not unusual to find pain and dysfunction in the fingers in association with tenosynovitis and this was frequently confused with " rheumatism" and median neuritis. Pain was always reproduced by pressure on the tendon sheath over the metacarpal head where a lump could often be felt. The injection was made into this area. He had treated nine patients in this manner with relief in all cases.

The afternoon session consisted of short papers.

Primary osteogenic tumours of the skeleton-Dr C. H. G. Price, Research Fellow in Pathology, University of Bristol, and Secretary of the Bristol Bone Tumour Registry, described the characteristics of osteochondroma and osteogenic sarcoma and analysed the cases that had been encountered in the Bone Tumour Registry at Bristol since its formation. These tumours had many features in common. The paper had been read in greater detail at the March 1956 meeting of the Bone and Tooth Society in London.

Pain of cervical origin-Mr $D$. M. Jones said that there were unrecognised clinical types of cervical disc lesions due to sensitivity of the discs, which he believed could give rise to pain and discomfort

Vol. 39 B, NO. 1, FEBRUARY 1957 
at the back of the throat with throttling sensations or the sensation of a lump in the throat or dysphagia. Conditions diagnosed as globus hystericus, or functional disturbance, might in fact be due to this cause, particularly in young people with no clinical signs or radiographic changes.

In discussing root pain, he said that pain was sometimes referred to a single muscle with tenderness in it which was a common complaint in the region of the shoulder and elbow. The sensory root stimulation gave rise to disturbance and shooting pains more peripheral in their distribution. Because of the relatively increased fixation in the foramina of the vertebrae, the nerve roots of old persons were more vulnerable to indirect violence, and they were often injured by jerks of the neck, blows on the shoulder or tugs on the outstretched arm. The resulting scarring could lead to intractable root pain in the absence of radiographic changes. A detailed history was important in such cases. He believed that not infrequently the painful and stiff shoulder and even tennis elbow might have a cervical origin.

Slipped femoral epiphysis-Mr D. R. Richard reviewed the traceable cases of slipped femoral epiphysis that had occurred in the Bristol area during the last fifteen years in thirty patients with thirty-seven affected hip joints. The longest follow-up was fifteen years, the average was five years. There were eleven acute cases. These were treated either by manipulation and internal fixation or by cervical wedge osteotomy. Four had good results, seven had aseptic necrosis. Heavy preliminary traction had been carried out before operation, without benefit. There were twenty patients with chronic epiphysiolysis, six of whom had bilateral slipping. The average length of history was seven months. Ten epiphyses were pinned in situ, all with excellent results. One was reduced by manipulation and was pinned, but the femoral head had undergone aseptic necrosis. In the cases with more severe displacement, seven cervical wedge osteotomies gave four good and three bad results, and four subtrochanteric osteotomies gave good results.

Discussion on amputation in relation to severe compound fractures of the tibia-Mr Keith Lucas opened this discussion by stating that the severe case was a very difficult problem, particularly when there was skin loss requiring plastic surgery. Mr G. M. Fitzgibbon of the Plastic Surgery Unit at Frenchay, said that often the efforts to save a leg that had extensive skin, soft-tissue and bone loss went too far, and that in many instances a primary amputation would have been more satisfactory and would have saved the patient much pain and suffering and a considerable amount of time. Late amputation was frequently necessary, but it was delayed because it was increasingly difficult for the surgeon dealing with the case to make the decision to amputate as time went on. The patient was therefore subjected to many reconstructive measures, often with indifferent results. The decision for primary amputation was a difficult one and in fact often was one which men of senior registrar rank found difficult to make because of lack of experience, and therefore a course of unwise conservatism was frequently adopted from the commencement. The controlling factor was mainly one of infection, because non-union was inevitable if this became chronic, and then amputation would follow. In some cases trouble might be avoided if a skin transfer by means of a cross-leg flap was performed at the initial operation. An additional blood supply was gained thereby. Diabetes and calcified arteries were probably indications for primary amputation. $M r E$. Mervyn Evans emphasised that the prevention of infection was dependent on immediate skin cover. Although many compound wounds could be sutured without excessive tension, nevertheless severe skin loss might necessitate a cross-leg flap. This was within the competence of most surgeons. The immediate transfer of a badly injured patient to a plastic unit from the periphery of the region was seldom possible.

Early diagnosis and treatment of congenital dislocation of the hip- $M r$ G. Blundell Jones showed a film which had been lent to him by Professor M. Ortolani of Ferrara, Italy, demonstrating how it was possible to make the clinical diagnosis of dislocation in young infants by obtaining a " jerk" by pressure on the knees with the legs in the flexed and abducted position after a manoeuvre of abduction in flexion. The jerk was caused by the head of the femur slipping over the posterior rim of the acetabulum. This jerk sign obviated the need for radiographic examination and in Italy was proving to be a tremendous boon in the early diagnosis in remote country clinics, where radiographic examination was not always possible. The film drew attention to the fact that in Italy congenital dislocation of the hip occurred more commonly during the winter months, a time when infants' lower limbs were bandaged tightly in swaddling clothes. Infant Welfare Clinics are doing much to diminish the incidence of congenital dislocation of the hip by making the infants wear " nappies" sufficiently large to keep the hips abducted.

Social events-The annual dinner was held in the evening in the Senior Common Room at Bristol University, and afterwards Mr Eyre-Brook gave a Lantern Lecture on his visit to the Fiji Islands, Gilbert Islands, Solomon Islands and New Guinea in June 1956. The lecture was profusely illustrated by coloured slides of a very high quality. Particularly interesting were those taken of a leper colony which he visited. Mr Eyre-Brook discussed the social, cultural and medical problems as they impressed a visitor. 
IRISH ORTHOPAEDIC CLUB

The Autumn Meeting of the Irish Orthopaedic Club was held on November 17, 1956, at St Joseph's Orthopaedic Hospital, Coole, Co. Westmeath.

There was a large attendance of members, who were entertained to lunch and tea by the Matron, Sister Finbar. The Orthopaedic Surgeons in charge of the hospital, Mr W. De Wytt and Mr Cecil McDowell, had organised an interesting and entertaining programme.

After preliminary discussion about the organisation of the orthopaedic service in that area, Mr De Wytt read a paper on his experiences of anterior inter-corporeal spinal fusion and showed some of his cases. This paper aroused considerable interest and gave rise to much discussion.

Mr McDowell discussed his experiences of excision of the outer end of the clavicle for arthritis of the acromio-clavicular joint.

An interesting paper on osteochondritis dissecans was given by Mr G. V. Osborne (Liverpool) who kindly attended the meeting as a guest.

After lunch the members toured the hospital and saw the new theatre block. There then was a series of interesting and stimulating clinical demonstrations.

\section{SOUTH AFRICA}

\section{SOUTH AFRICAN ORTHOPAEDIC ASSOCIATION}

FIFTH CONGRESS, 1956

The Fifth Congress of the South African Orthopaedic Association was held in Durban from August 13-18, 1956. The meeting was presided over by Mr C. T. Moller, the president of the Association. Distinguished guests from outside South Africa included Sir Walter Mercer from Edinburgh, Dr Steele F. Stewart from Honolulu and Mr F. Dwyer from Liverpool.

The meeting was a success from both an academic and social viewpoint, and was attended by thirty orthopaedic surgeons practising in South Africa and Rhodesia. A visit was made to the Umlazi Orthopaedic Tuberculosis Hospital, and members were entertained to a pleasant luncheon, and a tour of their factory, by the Cellona plaster-of-Paris company of Smith and Nephew. The annual dinner was marked by a tribute to Mr F. P. Fouché, the doyen of orthopaedic surgery in South Africa, who was presented with a silver salver bearing the facsimile signatures of all orthopaedic surgeons in our Association, in honour of his seventieth birthday.

Osteochondritis dissecans-Mr R. Percy-Lancaster (East London) discussed the condition as it affects the ankle and the elbow joints. He showed radiographs of these affected joints before and after operative removal of the loose fragments. The question of treatment led to some discussion. Mr J. M. Edelstein (Johannesburg) mentioned the rarity of reported cases affecting the capitulum, and Sir Walter Mercer (Edinburgh) indicated that unseparated areas in children would re-unite if immobilised for six months. If the fragment was separated it should be removed. Mr B. Polonsky (Johannesburg) mentioned a case in which he had removed the affected head of the radius.

Recurrent sprains of the ankle-Mr J. F. P. Mullins (Durban) dealt with the partial diastasis that occurs at the inferior tibio-fibular joint after a severe sprain of the ankle. These patients usually have a history of injury leading to recurrent sprains of the ankle. There is a sense of instability, with chronic pain after weight bearing, and the ankle tires easily. Radiographs usually show slight widening between the medial malleolus and the talus, and sometimes a positive inversion or eversion test. The most valuable sign is a click in the ankle which is elicited by rocking the talus from side to side with the ankle held in the neutral position. The degree of rocking indicates the degree of instability. Mr Mullins had operated on a large number of such ankles and had full details of twentyfive. Some patients had been followed up for six years, and all were relieved of their disability. The operation consisted of screwing the tibia and fibula together with a Johanssen lag-screw. The patient was kept in bed for two days and then allowed to walk. No plaster or compression bandage was necessary. The oldest patient treated was sixty-five, and he had had symptoms for twenty-five years. Mr Mullins had found that wiring of the bones or bony fusion of the inferior tibio-fibular joint was unsatisfactory. $M r T . B$. McMurray (Cape Town) said that a good test of instability of this joint was to force dorsiffexion of the ankle, which invariably gave rise to pain because it caused the inferior tibio-fibular joint to spread apart. Professor C. Lewer-Allen (Cape Town) preferred to fuse the tibia to the fibula two inches above the ankle joint by cross-flapping osteo-periosteal grafts across the gap, after removing the fibrous material between the bones. $M r C$. Kaplan (Durban) believed that, despite the normal movement that occurred at this joint, results seemed to indicate that this operation was sometimes necessary, but he would prefer to immobilise the ankle in plaster.

VOL. 39 B, NO. 1, FEBRUARY 1957 
Treatment of flat feet in children-Mr A. J. Helfet (Cape Town) had treated 500 cases of flat feet in children and foot strain in adults by means of heel-seats. He depicted by means of diagrams and photographs how the usual arch supports and wedged heels were ineffective in treating flat feet. The patient's heel merely slid laterally and deformed the outer stiffening of the shoe and wore down the heel. The usual complacent assumption that nature would correct most flat feet should be discarded. He had devised a heel-seat made of acrylic, which fitted snugly about the heel and corrected any tendency to valgus. It could be worn in any type of shoe, football-boot, gum-boot, sandal, tennis shoe or slipper. It held the heel in a vertical position and prevented the usual deformity of the shoe. It therefore saved expense on shoes, was comfortable, and did not need to be replaced more often than once or twice a year. It should be worn for about two and a half years. Mr J. J. Commerell (Cape Town) suggested that everted feet were due to a tight tendo calcaneus and that the relief obtained by heel-seats in these cases seemed to be due to the raising of the heel and therefore to the release of tension on this tendon. Mr C. T. Moller (Johannesburg) asked if the tight tendo calcaneus was cause or effect in these cases. The Whitman's valgus brace served a similar function as the heel-seat, but most technicians seemed unable to fit the patient accurately. Mr R. C. J. Hill (Durban) had noticed that when adolescent girls began wearing high heels they walked better and felt better, because of relief of the tight tendo calcaneus. In reply to $M r F$. P. Fouché (Johannesburg), Mr Helfet said that it did not matter what the cause of the flat feet was. Any child who persisted in walking on the inner borders of his feet could be treated by this method. The shape of a foot could be moulded by this appliance, just as the Chinese women used to mould their feet by binding them tightly.

Symposium on orthopaedic tuberculosis-Sir Walter Mercer (Edinburgh) opened the symposium by discussing the diagnosis and treatment of tuberculosis of the hip. He showed slides depicting the radiological appearances of the intra-articular and extra-articular types of hip tuberculosis, and emphasised the difference in diagnosis and treatment of these types. In the synovial types a biopsy assisted in the diagnosis and helped in treatment by decompressing the joint. Rest and antibiotics also assisted in the treatment. The action and dosage of the various chemotherapeutic substances such as para-amino-salicylic acid, iso-nicotinic acid hydrazide and streptomycin were mentioned. In the extra-articular types of tuberculosis of the hip, rest by leg traction and eradication of the bony focus was advisable, and the treatment of sinuses by chemotherapy and arthrodesis of the hip by Brittain's method were mentioned. A ciné film of the speaker performing a Brittain's arthrodesis by the posterior approach was shown.

Mr N. M. Thompson (Pietermaritzburg) described his results of excision of the head and neck of the femur in fifteen cases of tuberculosis of the hip in adults who had not responded satisfactorily to rest and chemotherapy. Most of these cases were acute, with pyrexia, pain, inability to walk, and sometimes discharging sinuses. The hip was opened by the anterior or lateral approach, sinus tracts and all affected soft tissues were excised, the neck of the femur was divided and the head scooped out. No attempt was made to dislocate the joint. The operation got rid of a great deal of tuberculous infected tissue; it opened up the tissues to chemotherapeutic agents, and put the affected acetabulum at rest, because weight bearing was now lateral to the acetabulum. A loose-fitting caliper was prescribed and gluteal exercises were practised. The patients, however, soon discarded the caliper and walked with one stick. They could walk up to six miles if capable of re-education, but heavy patients did not walk so far. Passive movements were usually full after the operation, but there was no active abduction. Shortening was usually one and a half inches. Mr Thompson believed that this operation should be done in all elderly patients in whom conservative treatment had failed.

Mr A. C. Boonzaier (Johannesburg) presented his results of central-dislocation-arthrodesis as a radical treatment of tuberculosis of the hip. He had operated on twenty-five patients with severe tuberculosis of the hip, of whom eighteen were adults. There was no operative mortality and in no case abscess or sinus formation. All the wounds healed primarily. Fourteen hips were healed solidly by fusion clinically and radiologically at the end of twelve months. Six hips were immobile clinically but showed evidence of non-fusion radiologically, although the patients were symptom-free. Two patients had slight movement at the hip but were without pain and able to walk. The other three patients had not returned for a final assessment.

The operation was performed as soon as the patient's general condition was satisfactory. Flexion contracture, if present, was first corrected by leg traction. A wide Smith-Petersen or antero-lateral exposure was employed, with division of the tensor fascia latae, a hand's breadth below the trochanter, osteotomy of the lesser trochanter, and detachment of the muscles from the greater trochanter. Every single bone abscess in the femur and acetabulum was ablated, and the entire capsule and all granulation tissue was excised. The sclerosed bone of the head, neck and acetabulum was broken down but the calcar femorale was left intact. The head and neck were shaped by osteotomes, and Charnley's reamers were used to drill a close-fitting hole in the acetabulum. If the acetabulum was ruined by the disease or the removal of debris a hole was made in the pelvis a little more proximally. The 
head and neck were dislocated into the pelvic hole, and multiple boiled cadaveric bone chips were laid across the fusion site. A full spica was applied for three months and another spica from the nipple line to above the knee for another three months. Weight bearing could be allowed in this latter spica if radiological union appeared to be progressing satisfactorily. Otherwise weight bearing should be delayed for a total of six months. The triad of para-amino-salicylic acid, streptomycin and isonicotinic acid hydrazide were given for twelve months.

It was considered that this debridement and fusion operation should be practised in all adults and children with grossly destroyed tuberculous hips. Radiographs were shown of nearly all the cases operated upon.

Mr C. J. Kaplan (Durban) presented his observations on local therapy in skeletal tuberculosis. He illustrated by means of slides and radiographs the additional efficiency of parenteral and intraarticular antibiotics and chemotherapy, in contrast with the previous treatment of rest, diet and sunshine alone. The previous duration of stay in hospital extending over three or four years was more than halved, and sinuses and secondary infection were almost completely eliminated. Streptomycin, $\frac{1}{2}-1$ gramme, was given intramuscularly daily for one month, and then every third day for the duration of stay in hospital. Para-amino-salicylic acid was no longer used as a routine because it tended to heal tuberculous lesions by fibrosis instead of by resolution without scarring. Iso-nicotinic acid hydrazide was given in doses of $\mathbf{8}$ to 16 milligrams per kilogram of body weight and was supplemented with vitamin B to prevent peripheral neuritis.

Some patients were treated in addition by intra-articular injections of streptohydrazid (a combination of streptomycin and iso-nicotinic acid hydrazide) twice weekly for three months. Radiographs were shown of tuberculous hips and knees which had regained painless function and useful mobility after this method of treatment.

Mention was made of the treatment of tuberculous spinal abscesses by means of drainage and continuous drip perfusion of the cavity with streptohydrazid in saline. A case of proved tuberculosis of the flexor tendon sheaths of the fingers had also been successfully treated by this drip perfusion method.

Mr J. J. Commerell (Cape Town) described the domiciliary treatment of orthopaedic tuberculosis as practised in Cape Town and its environs. During the last six years 410 patients had been treated on Thomas's frames or by other methods of immobilisation in their homes. Of these, 376 were cases of tuberculous involvement of spine, hips or knees. Most of these patients were under twenty-eight years of age. Older patients were difficult to treat at home because there was usually no one to attend to them. District nurses visited the patients regularly to give streptomycin injections and iso-nicotinic acid hydrazide tablets, and to inspect the frames. Two hundred and eighteen patients were treated thus until the disease had become arrested. The average length of treatment was sixteen months for spinal tuberculosis and fourteen months for hip tuberculosis. Four patients died of various causes and 126 required admission to hospital for various complications or because of inability to continue treatment at home. There now remained only twenty-eight patients on Thomas's frames at their homes, which proved that a large back-log of skeletal tuberculosis had been cleared up by early diagnosis and adequate chemotherapy and rest.

Dr H. G. Houghton (Durban) discussed recent trends in the treatment of tuberculosis, with special emphasis on pulmonary and cerebrospinal pathology. He made the following notable points. At the end of treatment 10 per cent of patients still had tubercle bacilli in their sputa. Para-aminosalicylic acid was no longer given routinely. Iso-nicotinic acid hydrazide was given in dosage of 15 milligrams per kilogram of body weight daily. Streptomycin was given in doses of 1 gramme per day. Ten per cent of patients became resistant to iso-nicotinic acid hydrazide and new drugs such as Neotocide and Dipasic were being tried. At the present time 2,000 patients with pulmonary tuberculosis in Durban were being treated outside hospital as ambulant patients. The value of bed rest was being challenged. The length of treatment was usually two years. Calcified foci in the lung should be treated.

The Durban mystery outbreak resembling Icelandic disease-Mr R. C. J. Hill (Durban) opened the discussion by informing the members of an epidemic of a disease resembling poliomyelitis which occurred in Durban in March 1955. The main features were a pyrexial illness followed by weakness of the trunk and limbs, clonic contractions of muscles, sensory changes and relapses of these symptoms. The condition persisted with periodic relapses for many months and was often associated with psychological changes in the patient. Ninety-eight members of the nursing staff of the Addington Hospital in Durban had been affected, and forty-five patients had developed the disease. Twelve of the nurses and four patients had become permanently incapacitated. Only twelve of the patients were male and the vast majority were between eighteen and twenty-five years of age. $\operatorname{Dr} R$. W. S. Cheetham (Durban) divided the disease into a prodromal, an acute and a convalescent phase. He demonstrated a nursing sister who was still incapacitated. She had patchy loss of sensation in the

VOL. 39 B, NO. 1, FEBRUARY 1957

L 
lower limbs and developed clonic contractions on moving the left arm and leg against resistance. Weakness of the abdominal and back muscles was almost a constant feature of this malady. Dr $P$ Joubert (senior pathologist, Durban) described the routine investigations and specific methods adopted during the epidemic. In his opinion circumstantial evidence pointed rather to a virus than to a toxic agent. $\operatorname{Dr} R$. English (Medical Officer of Health, Durban) believed that the disease had some connection with the endocrine organs and hoped that the examination of urinary ketosteroids might be useful. Dr $R$. Percy-Lancaster (East London) had seen four cases in East London, and described the progress of one case in detail. He noted that in most cases the left side of the body was involved. He described the psychological aspects and the treatment that is sometimes necessary for these symptoms.

The management of scoliosis-Mr F. J. Hedden (Johannesburg) stated that although the management of scoliosis was still controversial it had in recent years gradually progressed along certain sane and definite lines. He outlined the clinical examination in a case of scoliosis of the spine and demonstrated the usefulness of radiographs, particularly of " bending" films. Idiopathic scoliosis was the commonest ( 80 per cent). Other causes of scoliosis were poliomyelitis ( 5 per cent); neurofibromatosis ( 2 per cent); congenital (less than 2 per cent); thoracogenic (less than 2 per cent); Morquio's disease (1 per cent); Friedreich's ataxia, and spastic paralysis. He classified scoliosis as either functional or structural. He then described the various types of idiopathic scoliosis. Lumbar scoliosis occurred in 26 per cent of cases and the prognosis was good. Thoraco-lumbar scoliosis occurred in 8 per cent of cases and also had a good prognosis. Thoracic scoliosis occured in 43 per cent and was the most important group, giving rise to the largest curves and producing the worst deformities. It occurred at three periods of rapid growth and might be described as infantile, juvenile or adolescent. The combined thoracic and lumbar scoliosis occurred in 23 per cent of cases and the prognosis was good. He discussed the treatment and mentioned the roles played by physiotherapy, corrective plaster beds, plaster jackets and spinal supports, and correction followed by spinal fusion in all the different types. He described the method of correction and fusion in detail. He employed the Risser turnbuckle jacket to obtain correction. He then tried to obtain a sound bony fusion of the whole of the primary curve if possible in a one-stage operation by means of refrigerated banked bone. The patient was kept recumbent for six months in the Risser jacket after fusion, and was then allowed up in a polythene jacket or if necessary in a Milwaukee brace. A year after operation radiographs of the primary curves were taken to exclude pseudo-arthrosis, and, if they were satisfactory, all external support was discarded.

Mr Hedden concluded that 5 per cent of patients with idiopathic scoliosis needed early fusion and correction, mainly in the thoracic type at the age of ten years, because of the bad prognosis. Fifty per cent of paralytic curves needed operation because of instability, symptoms or deformity. Early fusion was especially indicated in the thoracic type. Nearly all cases of neurofibromatosis needed early operation, but operation was only rarely necessary in the congenital type. He felt that scoliosis should be dealt with in a specialised clinic where adequate facilities and time were available.

Malignant bone tumours-Dr M. Findlay (Durban) discussed the diagnosis and treatment of bone tumours. Radiographs and slides were shown of the various tumours and the following points were mentioned. In osteoclastoma 50 per cent of the patients gained a favourable result if properly treated; 35 per cent of the tumours tended to recur and 15 per cent became malignant. The treatment of osteoclastoma was still controversial. Some believed that irradiation after curetting caused malignancy, but Dr Findlay disagreed; he considered it the best line of treatment. In osteogenic sarcoma it was best to irradiate the tumour first (with supervoltage if possible) and amputate the limb afterwards. The "five-year cure rate" ranged from 10 per cent to 23 per cent. Arteriography was mentioned as a method of differentiating an inflammatory from a neoplastic bone lesion, or in diagnosing malignancy at an early stage in a benign tumour. Arteriographs were shown depicting the various differentiating features such as "pallor," branching of vessels and arterio-venous communications.

Dysplasia of tendons of feet as a cause of congenital deformities-Dr Steele F. Stewart (Honolulu) compared the development of the foetal foot in the macaque, the gorilla and the human. He believed that the human foot was more primitive than the monkey's foot, and that it stood at the base of the primitive tree. If the tendons differentiated and developed earlier than normal in a human foetus arthrogrypotic and other deformities were more likely to be present at full-term. The longer it took for the foetal development of the tendons in the foot, the less were the gradations of these foot deformities at birth.

In club-foot deformities there was a definite expansion of the tendo calcaneus, which was attached more medially on the calcaneum than in the normal foot. The tendo calcaneus consisted of a flat superficial band formed from the inner head of gastrocnemius, and a flat volar or deeper 
band formed from the outer head of gastrocnemius. These closely applied flat bands could always be seen and separated. It was the deeper band from the outer head of gastrocnemius that was attached to the medial surface of the calcaneum in club foot. This observation had led him to devise a new operation to correct club-foot inversion of the heel. He detached the deeper band from its insertion into the calcaneum and found that the heel could immediately be everted more easily. He then divided the superficial band of the tendo calcaneus to gain length, and inserted the distal end of the detached deep head into the distal end of the cut superficial head. In this manner a more direct and straight pull on the calcaneum was obtained.

Other tendon anomalies in club foot were corrected at the same operation. The faulty dorsal expansion of the peroneus brevis was severed and transplanted volarwards. Also the anomalous bands of peroneus longus in its plantar tunnel were severed to allow free play of this tendon. Dr Stewart showed photographs of patients treated by this method whose deformities appeared to have been corrected without subsequent manipulations or plasters.

The peroneus longus tenolysis was also employed in certain types of flat feet. He found that in these flat feet, when the heel-valgus was corrected, the patient could not actively depress the first metatarsal head on to the ground. These patients therefore had a fixed supinated forefoot due to adhesions of the peroneus longus in its plantar tunnel. When these adhesions were severed the first metatarsal head could be actively depressed and the patients became free of deformity and discomfort. He had found that this type of flat foot was not common in the Negro.

In the discussion $\mathrm{Mr} J$. M. Edelstein (Johannesburg) mentioned that in the Bantu foot there was an extra insertion of tibialis anterior in 12 per cent, and the peroneus tertius was often absent. Other anomalies of tendon insertions in the foot occurred in 2.5 per cent of Bantu as compared with only 1.5 per cent of the white population, and one would therefore expect a greater incidence of club feet in the Bantu. This deformity did not, however, appear to be more prevalent in the Bantu than in the white population.

Osteotomy of calcaneum in the treatment of pes cavus-Mr F. C. Dwyer (Liverpool) presented a new approach to the treatment of pes cavus. The operation advised by him consisted in a subcutaneous division of the contracted plantar fascia and correction of the varus deformity of the heel by removing a wedge of bone from the outer aspect of the calcaneum. He submitted that by approaching the deformity from behind and overcoming the varus of the heel, the foot was rendered plantargrade, and therefore weight bearing exerted a corrective influence which resulted in progressive improvement of the deformity. The operation was mainly a prophylactic one and should be performed before there was gross structural deformity and while active growth was still taking place. He had done the operation sixty-three times in forty-seven children, their ages varying from three to sixteen years. Even in patients over the age of sixteen great improvement was obtained by doing nothing more than this operation. There was improvement in their gait and shoe-wear; and the drop-foot and claw-toe deformities were strikingly corrected. In adults with fixed forefoot deformity the cavus could be corrected at the same time by removing a dorsal wedge from the tarso-metatarsal region, thus preserving movement at the midtarsal subtalar joint. Mr Dwyer showed photographs and radiographs of patients on whom this operation had been performed, and also a film illustrating the operation.

\section{CANADA \\ CANADIAN ORTHOPAEDIC ASSOCIATION}

The following officers were elected in June 1956. President, Dr Louis-Philippe Roy; Vice-president, Dr J. A. Leo Walker; President-elect, Dr G. W. Armstrong; Secretary-treasurer, Dr Ian W. Davidson.

\section{INDIA}

\section{ASSOCIATION OF SURGEONS OF INDIA}

A regional meeting of the Orthopaedic Section of the Association of Surgeons of India was held at Patna on September 29-30, 1956. The following were notable among the many papers that were read.

Reconstruction of the hand in leprosy-Dr James $R$. Donaldson emphasised the importance of careful selection of cases and showed results of sublimis tendon transplants in cases of advanced ulnar nerve paralysis. It has been his experience that these reconstructive procedures can be successfully performed even in the presence of anaesthesia and bacteriologically positive cases. Dr Donaldson also mentioned the usefulness of transplanting the tibialis posterior muscle to control drop-foot.

VOL. 39 B, NO. 1, FEBRUARY 1957 
Recurrent dislocation of shoulder-Dr A. K. Mukherji emphasised the part played by some congenital factors in the causation of recurrent dislocation of the shoulder.

Experimental intra-articular fractures-Dr $S$. Chowdhury illustrated the marked superiority of early movement over immobilisation in the treatment of intra-articular fractures in experimental animals.

Efiect of epiphysiodesis on muscle tissue- $\operatorname{Dr} S$. S. Sen had found that early epiphysiodesis in growing goats caused specific wasting in certain groups of muscles of the limb which had been shortened by such a procedure, and emphasised the importance that this experimental work might have on epiphysiodesis performed for leg equalisation in human patients.

Experimental diaphysectomy-Dr $M$. T. Mehta reported a series of successful diaphysectomies performed in experimental animals and emphasised the place that this method of shaft replacement might have in the treatment of persistent bone infections.

Malunited Colles's fracture- $D r S$. S. Sen reported fifty cases of malunited Colles's fracture treated by excision of the lower end of the ulna and wedge osteotomy of the radius at the site of fracture, and showed some remarkably good results.

\section{HOLLAND}

\section{PROGRESS IN ORTHOPAEDIC SURGERY}

Our Corresponding Editor, Dr J. D. Mulder, writes: Since my last report in September 1955 there have been only a few important events in the field of orthopaedics in this country which may be of interest to readers of the Journal.

At the session of the Netherlands Orthopaedic Society in November $1955 \mathrm{Mr} \mathrm{J} . \mathrm{H}$. J. van der Kamp reported a successful scapulo-thoracic arthrodesis in a seventeen-years-old girl with progressive muscular dystrophy (Erb's disease). Function of the thoraco-scapular muscles in this patient had been completely lost, while the deltoid had retained sufficient force to abduct the arm. At operation a hole was made in the inferior angle of the scapula, and the sixth rib was cut obliquely in the flank and pushed through the hole in the scapula. The superior scapular angle was drawn to the midline and fastened to the interspinous ligaments with the aid of a strip of fascia lata. Firm fixation of the scapula and nearly full elevation of the arm were obtained.

At the same session $\operatorname{Dr} G$. Hellinga, endocrinologist in Amsterdam, gave a survey of the effect of sex hormones on skeletal growth in man. It is well known that these hormones not only accelerate growth but also promote skeletal maturation. Thus the eventual effect of the administration of sex hormones on body length may be positive, zero, or even negative. In girls with a tendency to overgrowth, rapid skeletal maturation and termination of growth can be obtained by the administration of oestrogens in monthly periods of three weeks together with a continuous daily intake of androgen substances.

Conversely, methyltestosterone promotes metaphysial growth but has little influence on skeletal maturation, and may thus cause an increase in the eventual body length. Several individual growth curves were shown which illustrated these points.

At the session of the Society in February $1956 \mathrm{Dr} \mathrm{J}$. Langham, Lecturer in Anatomy at the Free (Protestant) University of Amsterdam, described his experiments on the influence of thyroid hormone on embryonic development. His experiments on rats showed that partial thyroidectomy before or at the beginning of pregnancy caused defects in the eye lenses and retinae of the embryo, disturbances of ossification, and formation of hare-lip. Antithyroid substances introduced directly into chicken or rat embryos caused delayed ossification, phocomelia and syndactylism.

In June $1956 \mathrm{Dr}$ A. J. Cohen published a doctorate thesis on avascular necrosis of the lunate bone. He reviewed the material of the State Accident Insurance Company (Workmen's Insurance) consisting of 148 cases of lunate necrosis, and was able to confirm previous work by Swiss investigators (Lang 1944, Ruttner 1946), stating that this necrosis was caused by subchondral fractures which can often be detected only with the aid of a special radiographic technique (oblique views and enlarged pictures).

In the summer and autumn of 1956 the country suffered a moderately severe epidemic of poliomyelitis, which caused an unusual number of respiratory palsies. Many patients were treated successfully with the aid of tracheotomy and artificial insufflation with comparatively simple automatic devices (Poliomat). Of course, constant expert supervision is necessary to prevent and treat atelectasis and other complications. It is thought that the easy accessibility of the patient is a great advantage, as compared to the use of the iron lung and similar devices, which are reserved for patients with paralysis of respiratory muscles without damage to the bulbar respiratory centre.

\section{REFERENCES}

LANG, F. (1944): Zeitschrift für Unfallmedizin und Berufskrankheiten, 37, 23. RürtneR, J. R. (1946): Helvetica Chirurgica Acta. Supplementum, 1. 


\section{ITALY \\ ITALIAN ORTHOPAEDIC ASSOCIATION 1956 MEETING}

The forty-first annual meeting of the Italian Orthopaedic Association was held in Bologna, in the Main Hall of the Istituto Ortopedico Rizzoli, from October 18-20, 1956, under the presidency of Professor R. Zanoli.

The main subject, bone tumours, was divided into two parts: one on the primary tumours of bone, opened by Dr I. F. Goidanich, of the Orthopaedic Clinic of Bologna, and the second on metastatic tumours, opened by Dr V. Pietrogrande, of the Orthopaedic Clinic of Rome. The subjects were accurately reviewed by the speakers. Some important colour films on bone tumours were shown.

Italian members and associates participated in the discussion. Among those taking part were many distinguished guests, including Dr B. Boitchev (Bulgaria), Dr V. Sanchis Olmos (Spain). Professor A. Gruca (Poland) and Professors K. Niederecker, G. Hohmann and M. Hackenbroch (Germany).

\section{SPAIN AND SOUTH AMERICA}

We are informed that, beginning in 1957, the Journal Revista de Ortopedia $y$ Traumatologia Latino-Americana will be combined with Acta Ortopédica y Traumatológica Ibérica to form a single journal for all countries using the Spanish and Portuguese languages. The combined journal will be edited simulataneously in Madrid and Buenos Aires.

Under the name of Revista de Ortopedia y Traumatologia, Iberian Edition, it will appear in three numbers, in January, May and September; and three issues of the Latin American edition will be published in March, July and November.

The subscription price for each edition will be eight dollars, and for the combined edition (Latin American and Iberian volumes) sixteen dollars.

This amalgamation of the two journals is recognised as an advance that is important for all orthopaedic surgeons of the Spanish- and Portuguese-speaking countries, and also for those of other countries, for the new Review will publish articles from Spain, Latin America and Portugal.

\section{INTERNATIONAL SOCIETIES \\ SEVENTH INTERNATIONAL CANCER CONGRESS}

The seventh International Cancer Congress, sponsored by the International Union Against Cancer, will be held in London from July 6-12, 1958, under the presidency of Sir Stanford Cade. Congress headquarters will be the Royal Festival Hall. There will be two main sessions of the Congress: A. Experimental; and B. Clinical and Cancer Control. Special emphasis will be placed on hormones and cancer, chemotherapy, carcinogenesis and cancer of the lung.

Proffered papers will be considered only if submitted with an accompanying abstract (not over 200 words) before October 1957 and if dealing with new and unpublished work.

The registration fee for the Congress will be ten pounds or thirty dollars and the latest date for registration without late fee will be January 1, 1958. Registration forms and a preliminary programme will be available early in 1957 on application to the Secretary-General, Seventh International Cancer Congress, 45 Lincoln's Inn Fields, London, W.C. 2, England.

\section{INTERNATIONAL SOCIETY OF ORTHOPAEDIC SURGERY AND TRAUMATOLOGY} SEVENTH CONGRESS, 1957

The Seventh Congress of the International Society of Orthopaedic Surgery and Traumatology (S.I.C.O.T.) will be held in Barcelona, Spain, from September 16-21, 1957. The provisional programme is as follows: September 16-Opening of Congress. Discussion on "The influence of growth on the sequelae of bone and joint injuries." Openers: Dr P. L. Chigot (France); Dr W. P. Blount (U.S.A.); Professor Bryan McFarland (Great Britain); Professor J. Trueta (Great Britain). September 17Discussion on “The treatment of flail limbs." Openers: Dr G. Hohmann (Germany); Dr M. Bastos-Ansart (Spain); Professor O. Scaglietti (Italy). September 18-Symposium on "Giant-cell tumours and their treatment." Symposium on "The surgical treatment of osteoarthritis of the hip (excluding arthroplasty)." September 19-Symposium on "Causes and prevention of congenital malformation of spine and limbs." September 20-Other papers.

Members and others wishing to attend the Congress should notify the Secretary-General before July 15, 1957. Members wishing to participate in the main discussions on the first two days should inform the Secretary-General of their intention and submit to him before June 15 a summary of their contributions. Other papers will be limited to ten minutes each. Those wishing to read papers should communicate with the secretary of the National Committee of their own country. The Secretary-General of the Society is Dr Bailleux, 34 Rue Montoyer, Brussels, Belgium. 